\title{
Technological Research of Zinc Extraction from Elazığ Simitsonite Ore
}

ISSN: 2576-8840

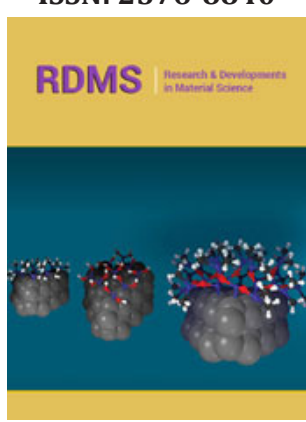

*Corresponding author: M Deniz Turan, Department of Metallurgical and Materials Engineering, Frrat University, Turkey

Submission: 墭 November 09, 2020

Published: 制November 20, 2020

Volume 14 - Issue 3

How to cite this article: Hasan Nizamoğlu, M Deniz Turan, Z Abidin Sarı, Aslıhan Demiraslan. Technological Research of Zinc Extraction from Elazığ Simitsonite Ore. Res DevMaterialSci.14(3).RDMS.000839.2020. DOI: 10.31031/RDMS.2020.14.000839

Copyright@ M Deniz Turan. This article is distributed under the terms of the Creative Commons Attribution 4.0 International License, which permits unrestricted use and redistribution provided that the original author and source are credited.

\author{
Hasan Nizamoğlu ${ }^{1}$, M Deniz Turan ${ }^{1 *}$, Z Abidin Sarı ${ }^{2}$ and Aslıhan Demiraslan ${ }^{1}$ \\ ${ }^{1}$ Department of Metallurgical and Materials Engineering, Firat University, Turkey \\ ${ }^{2}$ Department of Metallurgy Iskenderun Vocational School of Higher Education, Iskenderun \\ Technical University, Turkey
}

\begin{abstract}
In this study, the exraction of zinc from simitsonite $\left(\mathrm{ZnCO}_{3}\right)$ ore was investigated. The effect of various leaching parameters on the zinc dissolution was studied. Investigating leach parameters are leaching temperature (298-338K), leaching time (5-360min), sulphuric acid concentration (0.1-4M), particle size $(-16,-200 \mathrm{mesh})$, liquid-solid ratio $(5-100 \mathrm{ml} / \mathrm{g})$ and constant stirring speed $(600 \mathrm{rpm})$. According to experimental results, zinc dissolution increased with increasing of leaching temperature and it was exractated zinc $92.83 \%$ optimum conditions of $318 \mathrm{~K}$ of leaching temperature. Under these conditions, iron dissolution was kept in minimum amount. In the leaching process with sulfuric acid, it is observed that zinc is extracted with high efficiency, but the lead remains in the form of sulphate.
\end{abstract}

Optimum conditions were obtained as; $\mathrm{H}_{2} \mathrm{SO}_{4}$ concentration of $1 \mathrm{M}$, leaching time of $30 \mathrm{~min}$, leaching temperature of $318 \mathrm{~K}$, particle size of $-74 \mu \mathrm{m}$, liquid-solid ratio of $10 \mathrm{ml} /$ gand stirring speed of $600 \mathrm{rpm}$. In this study zinc and iron extraction were obtained as $92.83 \%$ and $5.31 \%$ respectively.

Keywords: Zinc; Sulphuric acid; Leaching

\section{Introduction}

Zinc is primarily produced from sulphidic ores; however, some zinc is produced from oxide-carbonate ores and different secondary resources such as zinc ash, zinc dross, flue dusts of electric arc furnace, leach residues, etc. Pyrometallurgical and hydrometallurgical routes or their combination can be employed for treating secondary materials. The hydrometallurgical processes are regarded as more eco-friendly for treating such materials having a low zinc content $[1,2]$.

In the most common hydrometallurgical zinc process, $\mathrm{ZnO}$-rich calcine is first produced from sulphide or oxide-carbonate concentrates and then leached with hot sulphuric acid solution. After liquid/solid separation, the pregnant solution is purified and electrowon for metallic zinc production. In some plants (e.g., Çinkur, Kayseri, Turkey), the zinc leach residue is stockpiled for future lead recovery $[1,3]$.

Due to the extraction of zinc and formation of insoluble lead sulphate during sulphuric acid leaching, lead is concentrated in this residue. However, a significant part of zinc remains in the form of zinc ferrite (ZnO.Fe2O3) in the leach residue that accounts for the high zinc losses in such processes $[1,4,5]$. In this study, the recovery of zinc from simitsonite $\left(\mathrm{ZnCO}_{3}\right)$ ore was investigated. In for this purpose, optimum conditions for zinc extraction were determined.

\section{Material and Methods}

Simitsonite ores, supplied from (Elazığ-Turkey), was used for leaching experiments. The simitsonite ore was classified by sieving through a 200 mesh ( $85 \%$ passed of total mass), and this fraction was used in experiments. Chemical analyses of the simitsonite ore were carried out by ICP OES in clear supernatant that was obtained by the microwave assisted dissolution technique. Results of the chemical analyses are shown in Table 1. Mineralogical analysis of simitsonite ore was performed using an ICP-OES. 
Table 1: Chemical composition of simitsonite ore.

\begin{tabular}{|c|c|}
\hline Constituent & Composition \\
\hline $\mathrm{Al}$ & $0.08 \%$ \\
\hline $\mathrm{Ca}$ & $6.84 \%$ \\
\hline $\mathrm{Mn}$ & $0.01 \%$ \\
\hline $\mathrm{Fe}$ & $0.40 \%$ \\
\hline $\mathrm{Mg}$ & $3.31 \%$ \\
\hline $\mathrm{P}$ & $0.02 \%$ \\
\hline $\mathrm{As}$ & $0.44 \%$ \\
\hline $\mathrm{Pb}$ & $13.93 \%$ \\
\hline $\mathrm{S}$ & $0.04 \%$ \\
\hline $\mathrm{Cd}$ & $0.08 \%$ \\
\hline $\mathrm{Zn}$ & $25.09 \%$ \\
\hline
\end{tabular}

\section{Results and Discussion}

In this study, simitsonite ore was leached in presence of sulphuric acid solution for an economical research on zinc production. The studied leaching parameters are: $\mathrm{H}_{2} \mathrm{SO}_{4}$ concentration (0.1-4 M); particle size $(-16,-200 \mathrm{mesh})$; liquid-solid ratio $(5-100 \mathrm{~mL} / \mathrm{g})$; leaching temperature (298-338K); leaching time (5-360min) and stirring speed (600rpm). As shown in Figure 1, zinc dissolution increases with increasing of $\mathrm{H}_{2} \mathrm{SO}_{4}$ concentration until $1 \mathrm{M} \mathrm{H}_{2} \mathrm{SO}_{4}$ concentration. After this concentration, zinc extraction value reaches to plateau. The effect of particle size on the results was investigated (Figure 2). As seen in Figure 2, zinc dissolution increases with decreasing of particle size. The effect of liquid-solid ratio on the results was investigated (Figure 3). As seen in Figure 3 , zinc dissolution increases with increasing of liquid-solid ratio it is seen.

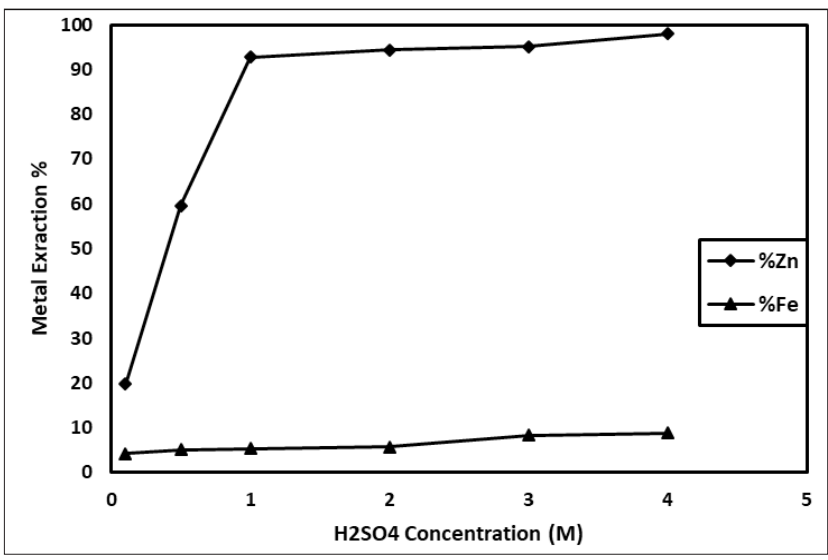

Figure 1: Effect of sulphuric acid concentration (Liquid- solid ratio: $10 \mathrm{~mL} / \mathrm{g}$; Stirring speed: 600rpm; Particle size: -200 mesh; Leaching time: 30min; Leaching temperature: $318 \mathrm{~K})$.

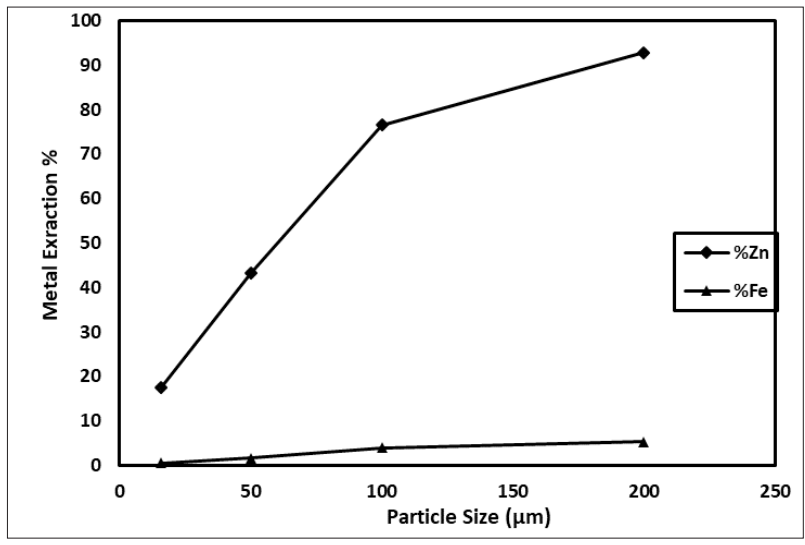

Figure 2: Effect of particle size (H2SO4 Concentration: 1M; Liquid- Solid Ratio: $10 \mathrm{~mL} / \mathrm{g}$; Stirring Speed: 600rpm; Leaching Time: 30min; Leaching Temperature: 318K).

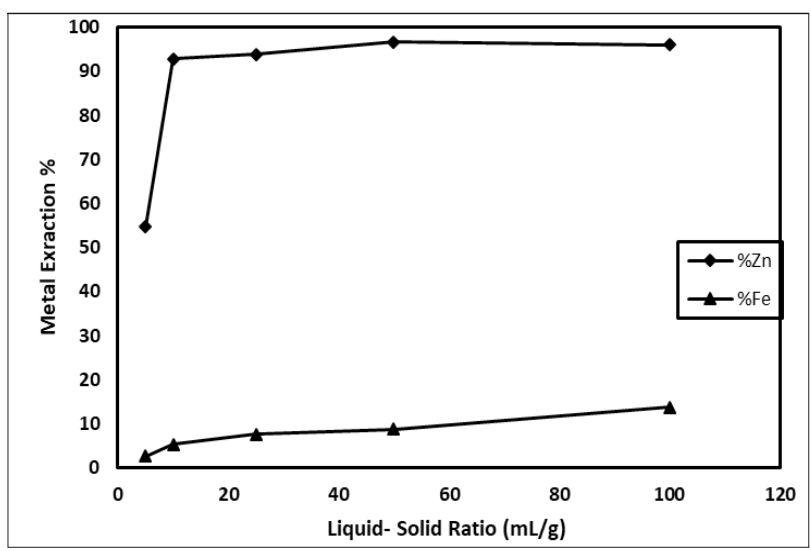

Figure 3: Effect of liquid- solid ratio (H2SO4 concentration: 1M; Stirring speed: 600rpm; Particle size:-200 mesh; Leaching time: 30min; Leaching temperature: $318 \mathrm{~K})$.

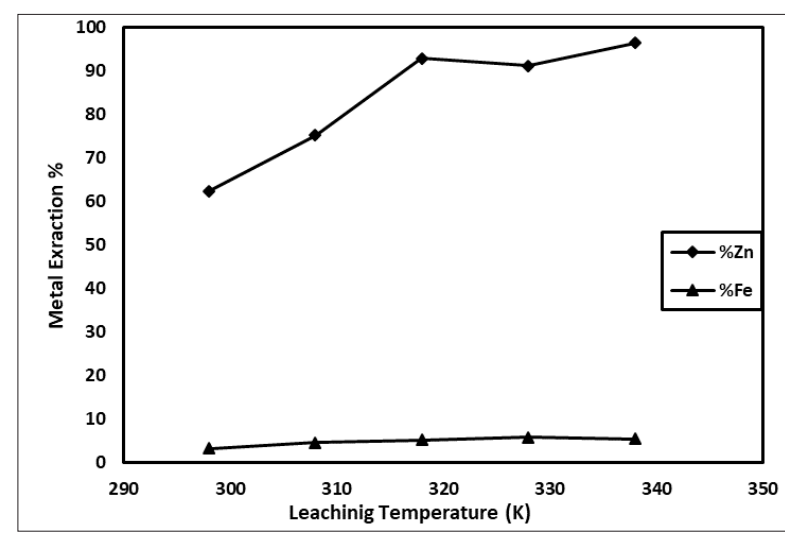

Figure 4: Effect of leaching temperature (H2SO4 concentration: $1 \mathrm{M}$; Solid-liquid ratio: $1 / 10 \mathrm{~g} / \mathrm{mL}$; Stirring speed: 600rpm; Particle size:-200 mesh; Leaching time: 30min).

Leaching temperature is an important parameter for metal extraction. In this study, sulphuric acid is significantly affected by 
temperature changing because of zinc dissolution rate increases with increasing of temperature. The effect of leaching temperature is given in Figure 4. Leaching experiments was carried out in range of temperature 298-338K. According to obtained results, it is clear that zinc dissolution increases with increasing temperature and it increases also increasing of leaching time.

The effect of leaching temperature on the results was investigated (Figure 4). As seen in Figure 4, zinc dissolution increases with increasing of leaching temperature. However, after $318 \mathrm{~K}$ of leaching temperature, extraction value has remained stable. The effect of leaching time on the results was investigated (Figure 5). As seen in Figure 5, zinc dissolution increases with increasing of leaching temperature it is seen. But after 30 minute it has remained stable.

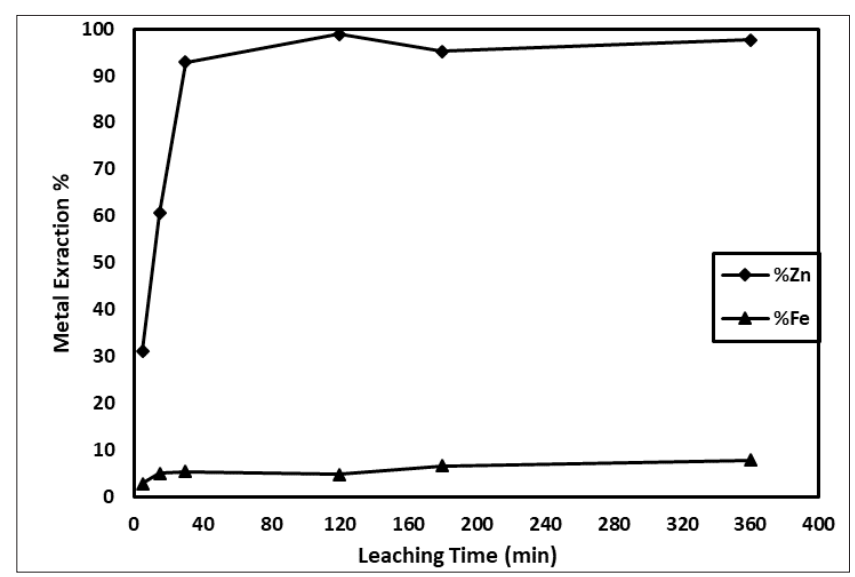

Figure 5: Effect of leachinig time (H2SO4 concentration: $1 \mathrm{M}$; Solid-liquid ratio: $1 / 10 \mathrm{~g} / \mathrm{mL}$; Stirring speed: 600rpm; Particle size:-200 mesh; Leachinig temperature: $318 \mathrm{~K})$.

\section{Conclusion}

Zinc extraction from Elazı $\breve{g}$ simitsonite ore was investigated in this study. The effect of five parameters $\mathrm{CH}_{2} \mathrm{SO}_{4}$ concentration, leaching time, leaching temperature, liquid-solid ratio, particle size) was investigated. Zinc dissolution increases with increasing of particle size, leaching temperature and leaching time. In the leaching process with sulfuric acid, it is observed that zinc is extracted with high efficiency, but the lead remains in leach residue as lead sulphate form.

Optimum conditions: $\mathrm{H}_{2} \mathrm{SO}_{4}$ concentration $1 \mathrm{M}$, leaching time $30 \mathrm{~min}$, leaching temperature $318 \mathrm{~K}$, particle size $-74 \mu \mathrm{m}$, liquidsolid ratio $10 \mathrm{~mL} / \mathrm{g}$ and stirring speed 600rpm is obtained. In this study, zinc and iron extraction is obtained $92.83 \%$ and about $5.31 \%$, respectively.

\section{Disclosure}

This study was presented at International Conference on Innovative Engineering Applications, CIEA' 2018, Sivas, Turkey was held.

\section{References}

1. Turan MD, Altundoğan HS, Tümen F (2004) Recovery of zinc and lead from zinc plant residue. Hydrometallurgy 75: 169-176.

2. Jha MK, Kumar V, Singh RJ (2001) Review of the hydro-metallurgical recovery of zinc from industrial wastes. Resour Consery Recycl 33(1): $1-22$.

3. Altundoğan HS, Erdem M, Orhan R, Tümen F (1998) Heavy metal pollution of zinc leach residues discarded in Çinkur plant. Doğa Türk J Eng Environ Sci 22: 167-177.

4. Abdel Basir SM, Rabah MA (1999) Recovery of metal values from brass melting slag. Hydrometallurgy 53(1): 31-44.

5. Addemir O, Açma E, Arslan C. Zinc System Publishing, Istanbul, Turkey. 